\title{
AN ACTIVITY-BASED MODEL OF CONCURRENT ENGINEERING SYSTEM
}

\author{
Goran D. Putnik*, Antonio José Caulliraux Pithon ${ }^{* *}$ \\ *Universidade do Minho, Department of Production and Systems Engineering, Portugal \\ putnikgd@dps.uminho.pt \\ ** Centro Federal de Educação Tecnológica-RJ, Brazil \\ pithon@cefet-rj.br, pithon@dps.uminho.pt
}

\begin{abstract}
The Concurrent Engineering (CE) concept is an advanced organizational concept based on idea of parallel/simultaneous and concurrent processing of the requirements of different business/enterprise's functions such as marketing, $C A D, C A M, P P C$, manufacturing, etc. which application leads to radical shortening of the total production process time as well as quality improvement. The CE based organization is oriented to product and, further, it is characterized by the much higher organizational dynamics than the traditional organizational models due to frequent products change. To support this dynamics effectively, and efficiently, it is necessary to develop corresponded models of the CE process that would serve as the base for the CE based organization design. The paper presents an activity-based model of CE System, using IDEFO diagrams as the representation class, covering the concrete $C E$ system's life cycle, that is composed of two basic global processes: the CE system design and the CE system operation. The model refers, as well, the CE tools and control (management) processes for the $C E$ processes presented.
\end{abstract}

\section{INTRODUCTION}

Presently, with the appearance of new technologies, enterprises are seeking a better positioning in the market by means of a slimmer production process that allows them to become more competitive in the launching of new products in less and less time spaces. One of the solutions found by companies at the beginning of the 80' was the migration of traditional organization (organization characterized by sequential processing), whose capacity of fast reconfiguration, high productivity and low cost no longer reached the parameters of the present demanding market, for the increase of parallelism among development activities, i.e. activities that were performed solely after final approval of previous activities are anticipated in such manner that they no longer depend on prolonged approval cycles.

This concept is called Concurrent Engineering (CE). Thus, the Concurrent Engineering (CE) concept is an advanced organizational concept based on idea of parallel/simultaneous processing of the of different business/enterprise functions' requirements such as marketing, $\mathrm{CAD}, \mathrm{CAM}, \mathrm{PPC}$, manufacturing, etc. which 
application leads to radical shortening of the total production process time as well as quality improvement. The basic mechanisms for the implementation of parallel/simultaneous processes are the multifunctional teams (called also the "taskforce"), that work together simultaneously, and the corresponded information technologies and tools for the $\mathrm{CE}$ process support. As the team works simultaneously it is not possible to process more than one single product at the time. From the other hand, changing to the new products implies reconsideration of the team structure as well as it may imply other CE support tools. Therefore, the traditional "functional" organization of the enterprise is affected and it is imposed a new product (project) oriented organization, based on product (project) oriented engineering teams to perform necessary tasks. This kind of organization sometimes is called the "orthogonal organization" (as opposite to the functional organization), "matrix organization", "horizontal organization", and similarly, and it is characterized with the much higher organizational dynamics than the traditional one.

To support this dynamics effectively, and efficiently, it is necessary to develop corresponded models of the CE process, or processes, that would serve as the base for the CE based organization design and, further, it's effective and efficient implementation and operation. In the paper it is presented an activity-based model ${ }^{1}$ of CE System, using IDEF0 diagrams as the representation class, covering the concrete CE system's life cycle, that is composed of two basic global processes: the $\mathrm{CE}$ system design and the $\mathrm{CE}$ system operation. The $\mathrm{CE}$ system design process is further decomposed in five sub-processes, covering the design of $\mathrm{CE}$ groups, selection of $\mathrm{CE}$ tools, etc., and the $\mathrm{CE}$ system operation processes are decomposed in eight sub-processes, covering the product life cycle. The processes are supported by/use corresponded $\mathrm{CE}$ tools as well as the processes are subjected to control (management).

Before we introduce our model of CE System, it is worth mentioning that the authors who work in area of Concurrent Engineering, e.g. (Causing 1989), (Pawar 2000), (Prasad, 1997), approach the theme only so far as it deals with definitions, principles, never referring to a model aimed at a CE Systems Project. Actually, we find only in (Ranky 1994) a CE specified explicitly from the system point of view.

IDEF0, used for the CE model representation proposed herein, is a graphic modelling language, which is a semi formal representation of sequences and hierarchy of processes, consisting of activities and functions in as many levels deemed necessary. The IDEF0 basic construct is an activity, or process, represented (graphically) by a box, Input and Output of the activity/process and Mechanisms that an activity/process uses. Additionally, each activity/process is subjected to Control. Input, Output, Mechanisms and Control are represented (graphically) by arrows.

The IDEF0 is also a representation class for the system's/enterprise's "workflow" representation.

\footnotetext{
${ }^{1}$ A model of a system/organisation/enterprise is created in order to represent a system/organisation/enterprise that serves as reference common to all its members, whether people, systems or resources. Based on the model of the system/organisation/enterprise, any person can acquire a general view of the operations of the system/organisation/enterprise, thereby enabling a deeper analysis and identification of points for improvement.

A strict definition of the model is (Ebbinghaus et al., 1996): "For a given formula, a model of this formula is any interpretation taken as true".
} 
The advantages of this diagram can be summarized by: 1) easy use, because a quick reading can provide a view of the entire process; 2 ) it permits the use of texts and glossaries, which results in a complete understanding of the processes and eliminates misinterpretations. The disadvantage of IDEF0 is that it is not able to represent the simultaneity and concurrency of processes.

The model described covers the activities of a traditional enterprise, but may also be applied to virtual enterprises with some alterations.

\section{CONCURRENT ENGINEERING}

The concept of $\mathrm{CE}$ defines that various activities are developed in parallel, interactively and concurrently, involving professionals from different specialties, covering the entire product development cycle, as opposed to the traditional sequential stage method. Thus, one activity is re-fed by another. Additionally, the activities/functions concur among themselves in order to achieve the best possible solution. This new manner of working is very beneficial in that it avoids possible losses of time and resources, as well as it minimise the design and manufacturing processes changes, caused by a lack of complete involvement of the different sectors in all stages of development that form part of the project, besides the improvement of development quality. To the contrary, the time and resources spent in the performance of tasks that would later have to be re-done would never be recovered (Pithon, Putnik; 2001).

The Concurrent Engineering Reference Model proposed (Putnik, 2000a) is multidimensional. On the figure 1 is presented a three-dimensional CE subspace where the first dimension presented is a CE application domain dimension, i.e. the product domain. In principle, the $\mathrm{CE}$ can be applied to any kind of product: "traditional" tangible products, services (e.g. client relationship), processes (e.g. manufacturing processes), information, (enterprise) system, etc. The second dimension is the EC process dimension that defines three types of $\mathrm{CE}$ processes, the $\mathrm{CE}$ process planning (or design), the EC processes themselves and the EC processes control (or management). The third dimension is the technology dimension i.e. the third dimension refers the methods (algorithms, procedures) and Hardware/Software (concrete) tools for the process support.

Other dimensions are considered too, e.g. the dimension of the CE system components and their relationship that represents the $\mathrm{CE}$ system organisation dimension.

Regarding this dimension, the CE concept is characterised by use of the multifunctional teams (also known as taskforces) that are the basic mechanism for the installation of parallel/ simultaneous and concurrent processes. The team/group leader, besides its leadership function (that includes group management and other aspects of the group leadership), serves also as the linking element between the directors and the group (members), figure 2 (Pithon, Putnik; 2002). 


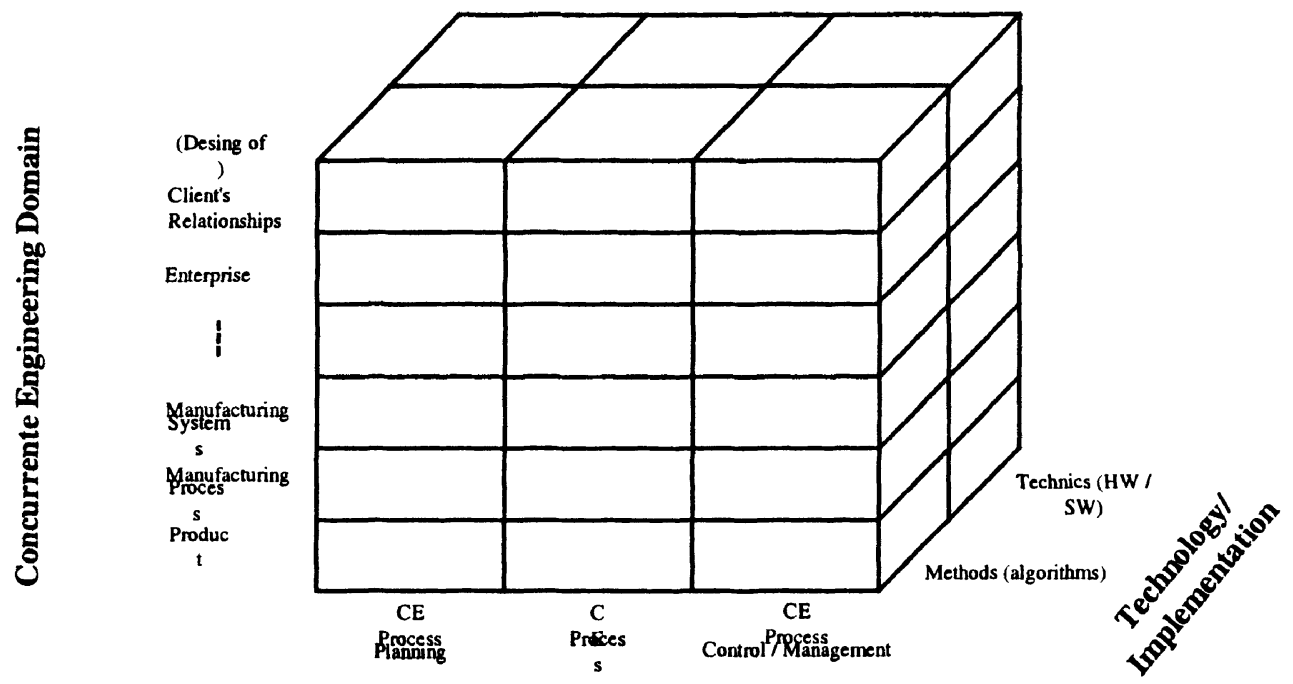

Concurrent Engineering Processes

Figure 1 - Concurrente Engineering Reference Model

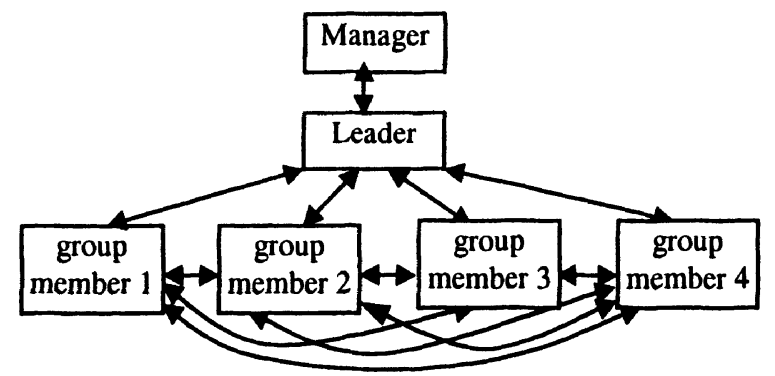

The model described in section 3 is oriented to the first layer of the reference model but can be applied to any other layer considering particularities of the concrete layer.

Figure 2 - Management Model of Concurrent Engineering Group

\section{CE SYSTEM MODEL}

There are various definitions of a system. One says that a (general) system is a relation over (set of) objects while another adds operations to the system specification, etc. For our purposes, our definition should satisfy the CE Reference Model (figure 1) as well. In accordance with the $\mathrm{CE}$ reference model, at the figure 1, to define a CE system it is necessary to define (1) CE domain, (2) CE processes and (3) technology (methods and techniques).

Considering the CE reference model referred and the following use of IDEF0 technique it is easy to find a correspondence between these two representations. In IDEF0 the CE domain is represented by the Input/Output arrows, (2) CE processes are represented by the activity/process box and the Control arrow (as the Control itself is a process), and (3) technology (methods and techniques), i.e. tools, is represented by the Mechanism arrow.

The section 3.1 presents the CE System model aimed primarily at "traditional" enterprise. The model is also applicable to the Virtual Enterprises (VE) with some 
additional specific information flow that is represented on the same figures by the thick grey dashed line. In section 3.2 are presented some specific sub processes regarding $\mathrm{CE}$ in $\mathrm{VE}$.

\subsection{CE System Model Aimed at "Traditional" Enterprises}

In order to describe the model at its highest level, an $\mathrm{A} 0$ context diagram has been created (figure 3 ) where by the box $\mathrm{A} 0$ is presented the global CE process (Pithon, Putnik; 2001).

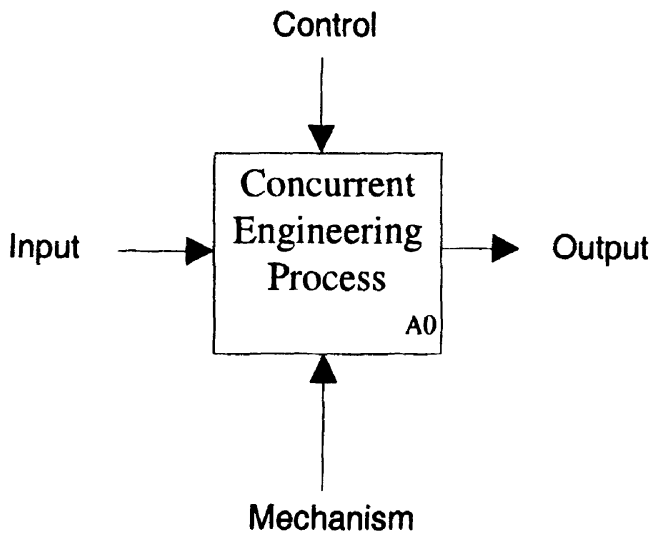

Figure 3-CE System global model - (Diagram of A0 context)
Decomposition of the process A0 is shown in diagram on the figure 4 . We have two global sub processes which are: the $C E$ System design (A1), which corresponds to the $\mathrm{CE}$ process planning from the $\mathrm{CE}$ reference model at the figure 1 , and of the CE System operation (A2), which corresponds to the (objective) $\mathrm{CE}$ process and the $\mathrm{CE}$ process control, or management, from the $\mathrm{CE}$ reference model at the figure 1 .

It is important to notice that the diagram on the figure 4 serves as a model for the "traditional"

enterprise as well as for the VE with the difference in the information flow represented by the thick grey dashed line (that will be explained in the section 3.2).

The Al process, i.e. the CE System design process, is consisted of five subprocesses, see figure 5, that cover CE team design (A11), selection of software/tools for CE teams (A12), CE team management methodologies (A13), development of (software) tools for CE teams (if necessary) (A14), and the training of the CE team in the use of new tools (if necessary) (A15).

The A2 process, i.e. the CE System operation process, is consisted of eight subprocesses, see figure 6, that cover all aspects of the entire life cycle of product, from Market Research (for new products to be produced by the enterprise with the objective of meeting the client's needs) to After Sales service. These are: market research for a new product (A21), product specification (A22), product project and development (A23), refinement and construction of prototype (A24), pre-production (A25), production (A26), distribution (A27), and after sales service (A28).

It is worth to notice that eight sub-processes referred correspond by the names to the general product life cycle, which is, in fact, the objective of the CE concept, but they are not the processes along the product life cycle. They are true CE processes that refer particular aspects of the product life cycle. CE approaches the product development by multifunctional team composed by experts for different aspects of the product life cycle. Each one of these experts perform one of the CE processes in accordance with its expertise, which is implicitly represented by CE processes which names associate to the particular general product life cycle. Consequently, more correctly, we could say that the processes A21-A28 are: CE process that considers 
market research for a new product (A21), CE process that considers product specification (A22), CE process that considers product project (A23), etc.

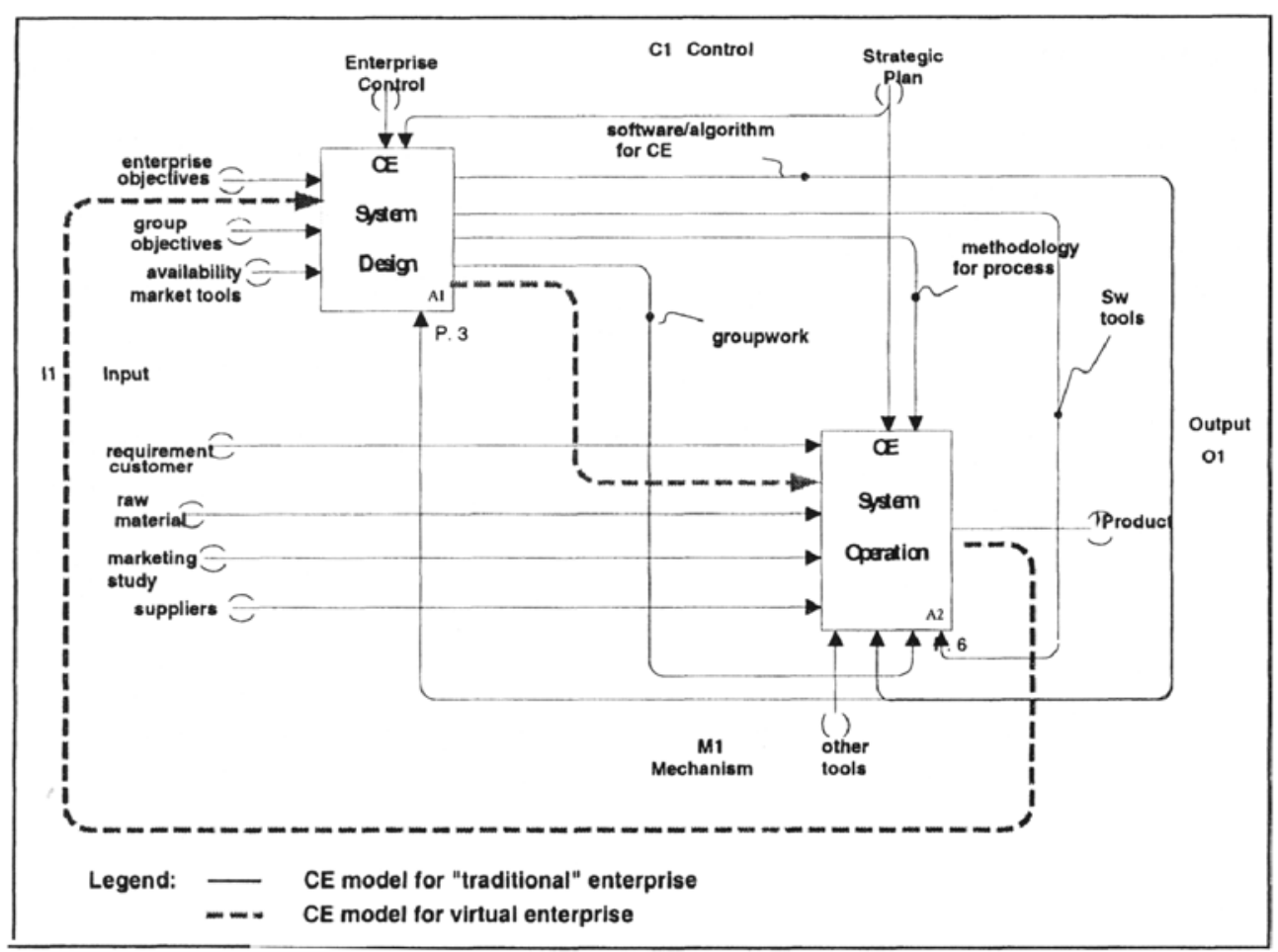

Figure 4-CE System design and operation (decomposition of A0 diagram)

Naturally, there are other possible decompositions of the A2 process. Also, different association with the CE team members (CE operations definition ${ }^{2}$, which is not the issue in this paper) are possible, e.g. one A2x process could be performed by one, two, or more EC team members as well as one team member could perform one, two, or more $\mathrm{CE} \mathrm{A} 2 \mathrm{x}$ processes.

The processes A21 to A28 should be performed simultaneously and concurrently, as it is the CE principle. However, the processes A21 to A28 are presented sequentially in the figure 6 due to the IDEFO incapacity to represent correctly the simultaneity and concurrence of the processes. The simultaneity and concurrence of the processes could be represented in IDEF0 diagrams by the

${ }^{2}$ By the operation we consider the set of processes allocated to one resource. In the context of "Operation" one processes is called the "Operation element". For example, if we have to drill two holes and if we allocate drilling of each one hole to two different machines that we will have two operations, each operation with one operation element. If we allocate drilling of both holes to only one machine than we will have only one operation and this operation will have two operation elements. The similar concept is applied to services, in our case to the CE processes, where the "machine" is a human expert that performs one or more processes. Note: The $\mathrm{CE}$ processes in this paper do not consider the $\mathrm{CE}$ operations in the above sense as it is the issue of the concrete $\mathrm{CE}$ processes/CE team design solution. 


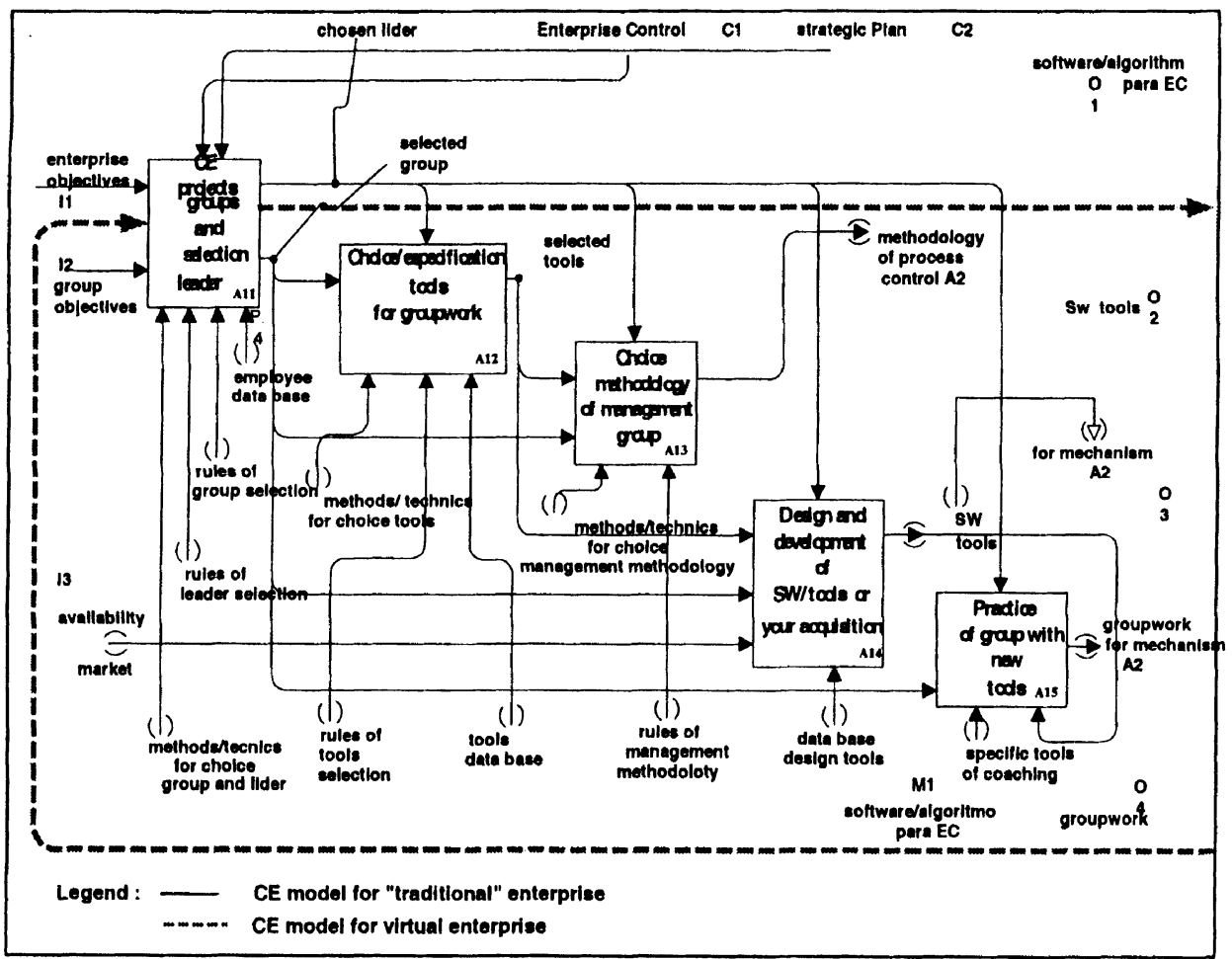

Figure 5 - CE System design processes (decomposition of A1 process)

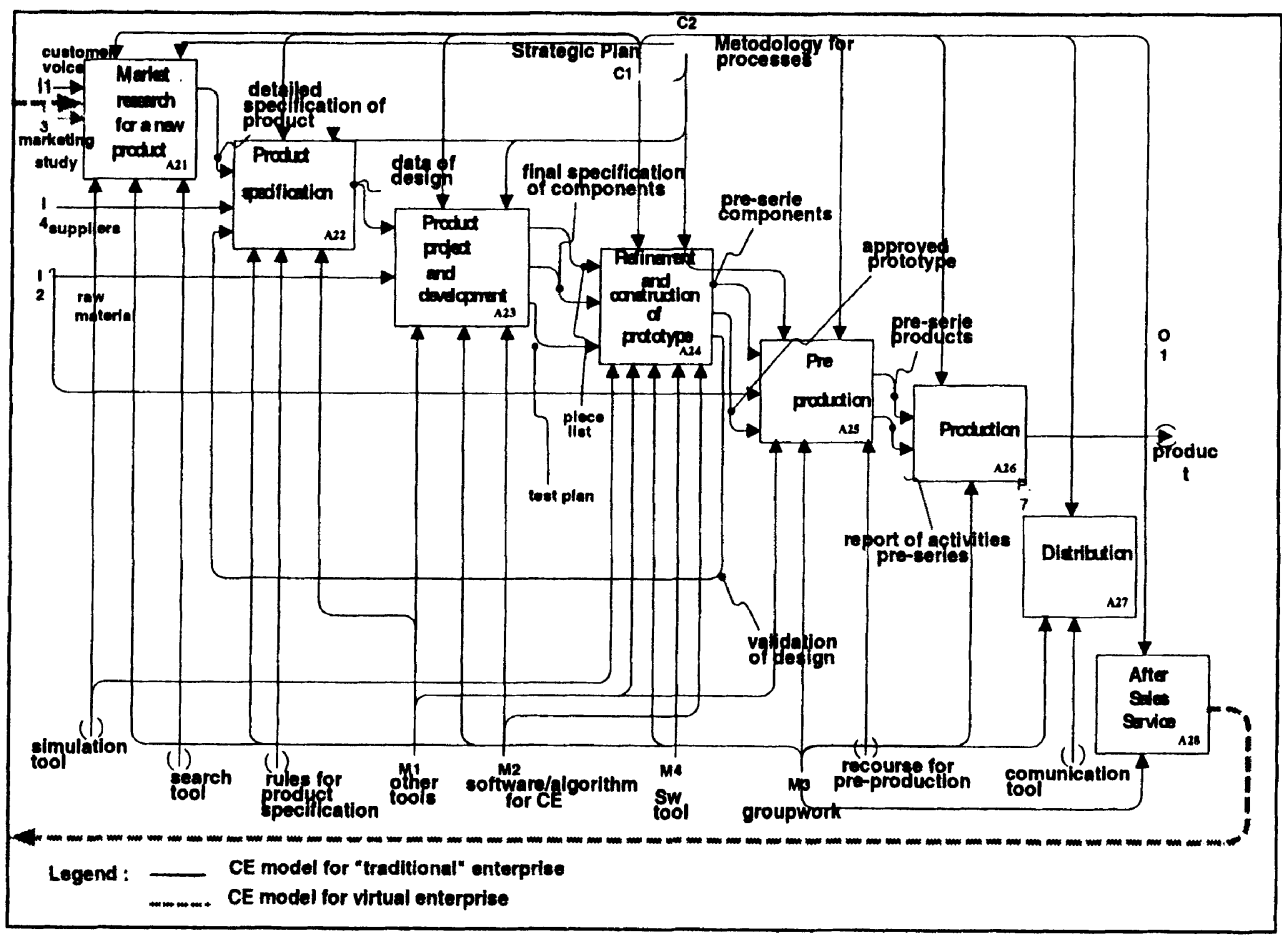

Figure 6-CE System operation processes (decomposition of A2 process) 
feedback information flow between each two processes together by the CE process control/ management that enters all sub process. Thus, the interpretation of the processes presented on the figure 6 and their relationship should consider their simultaneity and concurrence.

Due to the space limitation, of the further decomposition of processes it is presented only the decomposition of the A11 process, which, for the traditional enterprise, consists of the CE team leader selection (A111) and CE team constitution (A112), figure 7.

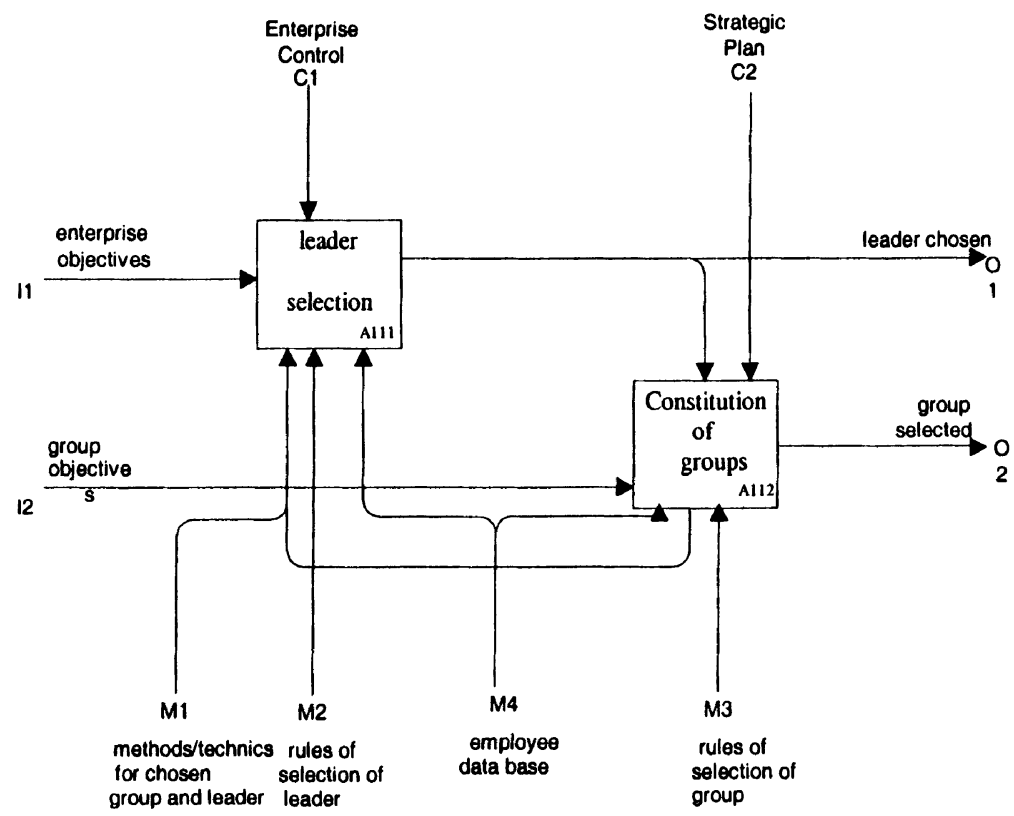

Figure 7-CE team design processes in "traditional" enterprise (decomposition of A11 process)

\subsection{The CE Model Aimed at Virtual Enterprises}

The elements of the CE System model for Virtual Enterprises are already presented in figures 4, 5 and 6. The main particularity is that CE system design and operation are performed also simultaneously and concurrently (while in "traditional" enterprise these processes are sequential), represented by a closed circle in figures 4 , 5 and 6 meaning that the $\mathrm{CE}$ system design has re-feeding from the $\mathrm{CE}$ system operation. In other words, the CE system is re-designed, or reconfigure, along the (objective and concrete) $\mathrm{CE}$ process. The principle agent of the $\mathrm{CE}$ system reconfigurability in VE is the broker (Putnik, 2000b), (Pithon, Putnik, 2002), as it is for the VE in general. The objective of this approach is improving the system's flexibility, through the $\mathrm{CE}$ team reconfigurability, i.e. the $\mathrm{CE}$ team members changes, figure 8 (Pithon, Putnik, 2002).

The further decomposition of the processes shows other particularities of the $\mathrm{CE}$ system model for VE. For example, the decomposition of the process A11 shows the broker selection process, figure 9, that doesn't exists in the CE system model for "traditional" enterprise. 


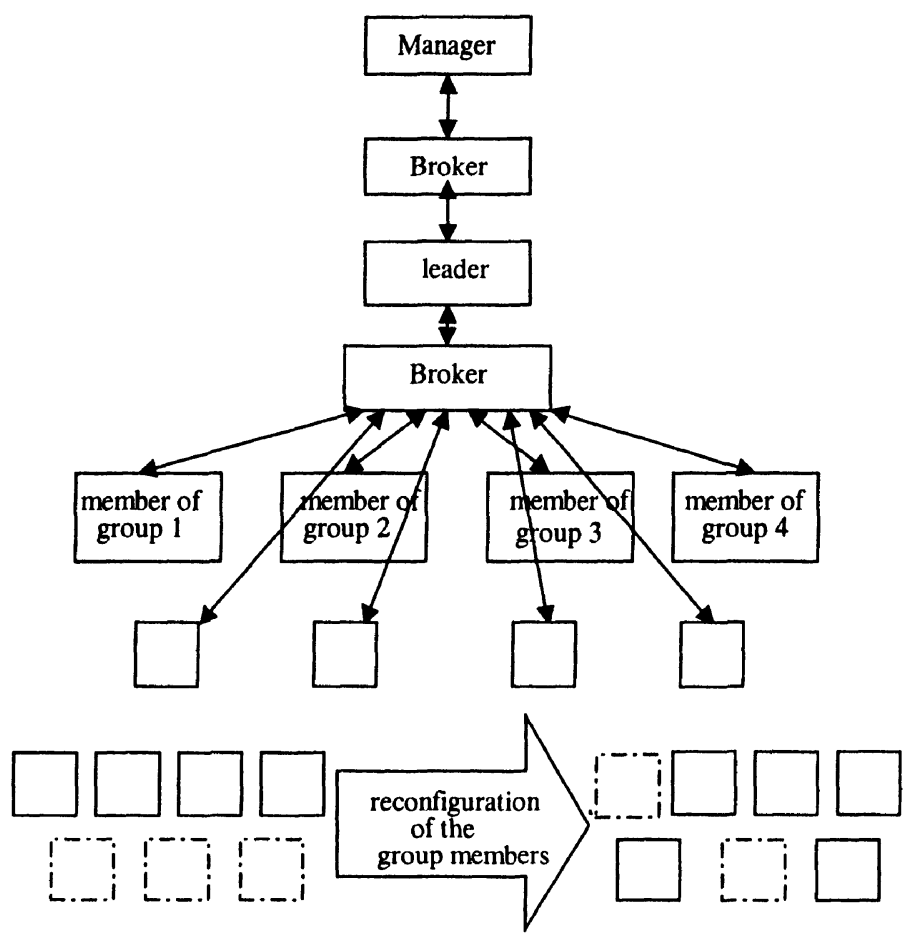

Figure 8 - Management model of CE teams in Virtual Enterprises

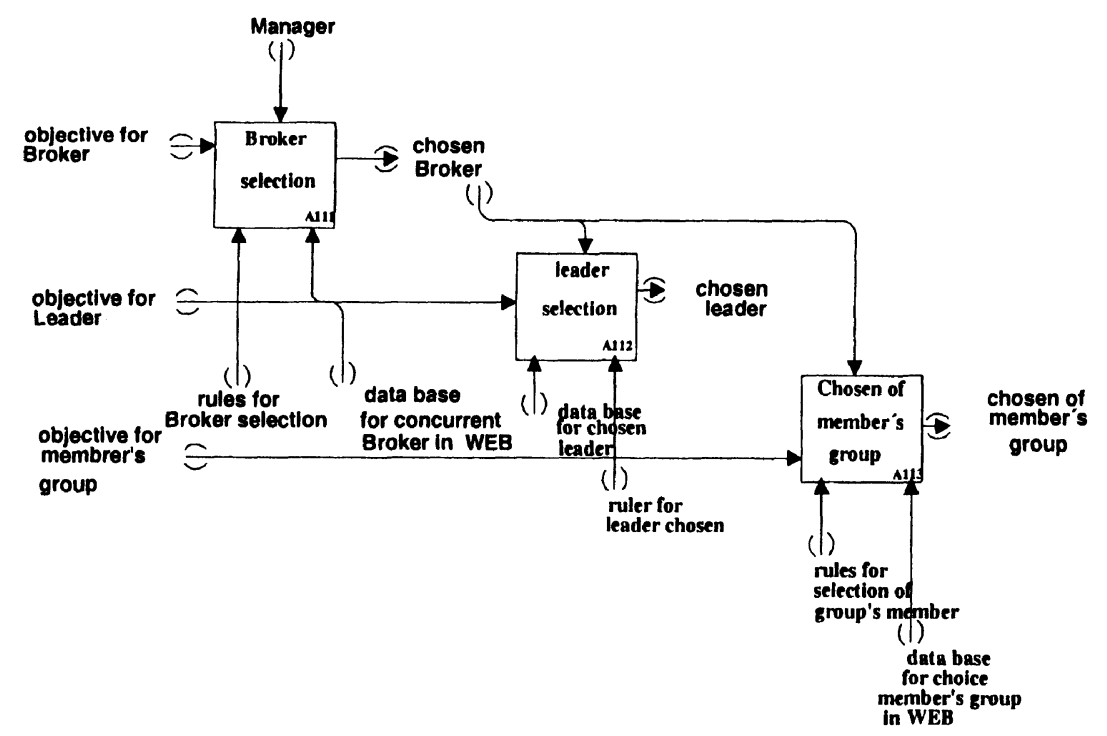

Figure 9-CE team design processes in Virtual Enterprise (decomposition of A11 process for CE teams in Virtual Enterprise) 


\section{CONCLUSION}

It is presented a model of CE system at the first place with the objective to serve as a reference for development and implementation of CE systems in "traditional" enterprises as well as in virtual enterprises. The model also represents a workflow for $\mathrm{CE}$ at a global/higher levels. On the second place, it is expected that it will contribute for further better understanding of the CE processes and systems.

The future work will aims at more detailed specification of the CE processes and systems, especially considering different application domains as well as the system's variability. It is planned application of some more formal specification languages, e.g. some of the Formal Description Techniques (FDT) as SDL, ESTELLE, LOTOS, or UML, in order to provide more efficient development and application of $\mathrm{CE}$ systems and CE system's tools and environments together with the issue of system's integrability. The author's special interest is development of CE systems in VE.

\section{ACKNOWLEDGMENTS}

We would like to thank FCT (Fundação para a Ciência e a Tecnologia - The Foundation for Science and Technology) of Portugal, for the financial support provided for this research.

\section{REFERENCES}

Causing, D. (1989). "Concurrent Engineering." American Society of Mechanical Engineers.

Ebbinghaus, H. (1996). Mathematical Logic, Springs

Pawar, K. S., Sudi (2000). "Virtual collocation of design teams: coordination for speed." International Journal of Agile Management Systems Vol. 2, no 2: 104-113.

Pithon, A; Putnik, G. (2001). Concurrent Engineering and Groupwork . Introduction; Technical Report, CESP-GIS-01-01, University of Minho

Pithon,A; Putnik G. (2002). Team Work for Concurrent Engineering in Agile/Virtual Enterprise by BM_Virtual Enterprise Architecture Reference Model; PRO-VE 2002, Kluwer (to be published)

Prasad, B. (1997). Concurrent Engineering Fundamentals, V.2, Prentice Hall

Putnik G. (2000a). Notes on Concurrent Engineering, MSc course on Industrial Engineering, University of Minho, Guimarães, Portugal

Putnik, G. (2000b). BM_Virtual Enterprise Architecture Reference Model. In A. Gunasekaran (Ed.), Agile Manufacturing: 21st Century Manufacturing Strategy (pp. 73-93). UK: Elsevier Science Publ.

Ranky, P. G. (1994). "Concurrent Engineering and Enterprise Modelling." Assembly Automation V.14, No 3 MCB University Press. 